\title{
Reflets
}

Revue d'intervention sociale et communautaire

\section{Un pouvoir à partager : les femmes francophones de l'Ontario dans la politique municipale et scolaire, état de la situation}

\section{Caroline Andrew et Linda Cardinal}

Volume 9, numéro 1, printemps 2003

Le genre en contexte : pratiques sociales et représentations

URI : https://id.erudit.org/iderudit/010868ar

DOI : https://doi.org/10.7202/010868ar

Aller au sommaire du numéro

Éditeur(s)

Reflets : Revue ontaroise d'intervention sociale et communautaire

ISSN

1203-4576 (imprimé)

1712-8498 (numérique)

Découvrir la revue

Citer cet article

Andrew, C. \& Cardinal, L. (2003). Un pouvoir à partager : les femmes

francophones de l'Ontario dans la politique municipale et scolaire, état de la

situation. Reflets, 9(1), 212-215. https://doi.org/10.7202/010868ar

Tous droits réservés @ Reflets : Revue ontaroise d'intervention sociale et communautaire, 2002
Ce document est protégé par la loi sur le droit d'auteur. L’utilisation des services d'Érudit (y compris la reproduction) est assujettie à sa politique d'utilisation que vous pouvez consulter en ligne.

https://apropos.erudit.org/fr/usagers/politique-dutilisation/ 


\section{Un pouvoir à partager : les femmes francophones de l'Ontario dans la politique municipale et scolaire, état de la situation}

Caroline Andrew et Linda Cardinal

Université d'Ottawa

Un rapport de la Table féministe francophone de concertation provinciale de l'Ontario sous la direction de Linda Cardinal et Caroline Andrew, Université d'Ottawa, pour l'Association française des municipalités de l'Ontario, 2002.

L'étude avait pour objectif d'inciter les membres de la francophonie ontarienne - les femmes en particulier - à faire davantage le saut en politique municipale. Elle servait ainsi à organiser des ateliers de formation pour ces dernières.

À cette fin, notre étude tentait de répondre aux questions suivantes : Pourquoi les francophones en général et les femmes francophones en particulier doivent-ils s'intéresser à la politique municipale et scolaire? Comment les conseils municipaux sontils répartis dans les régions désignées bilingues? Qui fait partie des conseils scolaires? Quelles sont les préoccupations des jeunes, des femmes et des membres des minorités raciales francophones de l'Ontario? Quels facteurs favorisent ou non leur participation à la politique municipale et scolaire?

Les prochaines élections municipales ontariennes auront lieu en 2003. D'ici là, l'Association française des municipalités de l'Ontario (AFMO) considère qu'il faut inciter les femmes, les 
jeunes et les membres des minorités raciales francophones à faire le saut en politique pour participer davantage à la gestion du pouvoir.

Pour la Table féministe francophone de concertation provinciale de l'Ontario, les prochaines élections municipales constituent également une source de préoccupations. Le domaine municipal est un lieu d'engagement de plus en plus important pour les femmes francophones, y compris les jeunes et celles des minorités raciales. Nous verrons toutefois dans cette étude qu'elles y sont toujours peu nombreuses. C'est pourtant à ce niveau que se prennent des décisions capitales pour elles dans les domaines suivants : sécurité publique, services sociaux, certains soins de santé, services aux femmes immigrantes et réfugiées ainsi qu'aux femmes des minorités raciales.

De plus, la population francophone de l'Ontario vieillit; l'apport des jeunes au développement du milieu est donc essentiel à sa survie et à son épanouissement. Dans ces conditions, il devient urgent de favoriser et de valoriser la présence des jeunes et des jeunes femmes au niveau municipal. L'intégration des nouveaux arrivants et des nouvelles arrivantes à la francophonie ontarienne passe également par une plus grande participation au pouvoir local.

Notre étude porte plus spécifiquement sur les femmes francophones dont les jeunes et celles des minorités raciales. Certes, les questions abordées pourront aussi être utiles aux francophones dans leur ensemble, mais elles sont avant tout destinées à encourager un plus grand nombre de femmes à faire le saut en politique locale. Ainsi, notre démarche se situe dans le prolongement des travaux de Lucie Brunet sur la question « femmes et politique " qu'elle a réalisés pour la Table féministe. Nous croyons, à l'instar de cette dernière, qu'il faut une plus grande parité entre les femmes et les hommes en politique.

Notre étude a aussi pour objectif de sensibiliser les francophones et les femmes francophones à la nécessité d'une réflexion plus poussée sur les fusions municipales et leur impact sur les services en français. La décentralisation et les fusions ont instauré 
un nouveau système dans lequel les municipalités ont de plus en plus de responsabilités à l'égard de la prestation des services publics. Selon l'Office des affaires francophones, 44 municipalités en Ontario offrent des services en français. Mais qu'en est-il véritablement depuis les restructurations?

Nous voulons souligner l'intérêt, voire l'urgence pour les francophones et les femmes francophones de prendre les moyens nécessaires afin de faire le saut en politique municipale et scolaire. Trop longtemps, on a véhiculé à cet égard l'image de réunions ennuyeuses passées à parler d'aqueducs et d'égouts. Ce stéréotype bien ancré dans les mentalités détourne souvent les personnes qui ont des préoccupations plus sociales et culturelles.

Notre étude s'est basée sur des données du recensement de 1996 sur la langue maternelle, le sexe et les minorités raciales francophones en Ontario, des statistiques de l'Office des affaires francophones sur les francophones de l'Ontario, les données touchant les municipalités dans les 23 régions désignées bilingues en vertu de la Loi sur les services en français, les sites Internet de l'AFMO, de l'Association ontarienne des municipalités, du ministère des Affaires municipales et du Logement, et du ministère de l'Éducation et des conseils scolaires.

Notre étude nous a permis de faire ressortir les conclusions suivantes:

- Il importe de penser à la relève francophone, dans sa diversité, car les moments de transition préparent l'avenir. Il faut donc s'activer maintenant pour aider à structurer les municipalités de demain et les rendre plus sensibles aux besoins des francophones.

- Il n'existe pas de liste officielle des municipalités bilingues en Ontario. Il est également impossible de confirmer s'il existe un continuum de services dans les municipalités des 23 régions désignées bilingues.

- L'arrivée toujours plus importante des francophones dans les villes ou les banlieues vient relancer le débat entre tenants des services homogènes francophones et partisans des services bilingues. Comment réaliser un tel débat sans menacer la cohésion du milieu francophone? 
- Selon la Table féministe francophone de concertation provinciale de l'Ontario les cinq principales revendications des femmes francophones de toutes origines ou de tous milieux concernent les services sociaux, les services de santé publique, l'accès et la mobilité, la sécurité et l'accès aux centres de décisions.

- Des questions qui devraient préoccuper les jeunes sont : la consultation et la participation aux structures décisionnelles des conseils scolaires. La place des jeunes dans le processus politique est revenu à l'ordre du jour depuis les années 1960, notamment en raison du vieillissement de la population.

- Les préoccupations des membres des minorités raciales au plan municipal sont également importantes. Soulignons le besoin de planification stratégique et de politiques touchant l'immigration, l'emploi et la lutte au racisme.

- Le pouvoir communautaire francophone est fragmenté et chancelant dans plusieurs domaines. La politique municipale constitue donc un espace d'action où les francophones pourraient davantage apprendre à oeuvrer comme collectivité. Ils devraient y exercer un réel pouvoir de décision. Le milieu municipal est un des seuls lieux avec le domaine scolaire où ils peuvent acquérir un certain pouvoir comparativement aux niveaux provincial et fédéral où leur nombre est peu significatif et leur pouvoir d'influence, presque nul. Il nous semble que cette question devrait préoccuper davantage les francophones qu'elle ne l'a fait jusqu'à présent.

- Le pouvoir municipal est également à partager entre toutes les composantes du milieu francophone. Ainsi, les femmes, les jeunes et les membres de minorités raciales doivent prendre leur place dans le développement local en vue de favoriser l'équité, l'intégration et la vitalité. La vie locale en dépend ainsi que l'avenir du milieu francophone. 